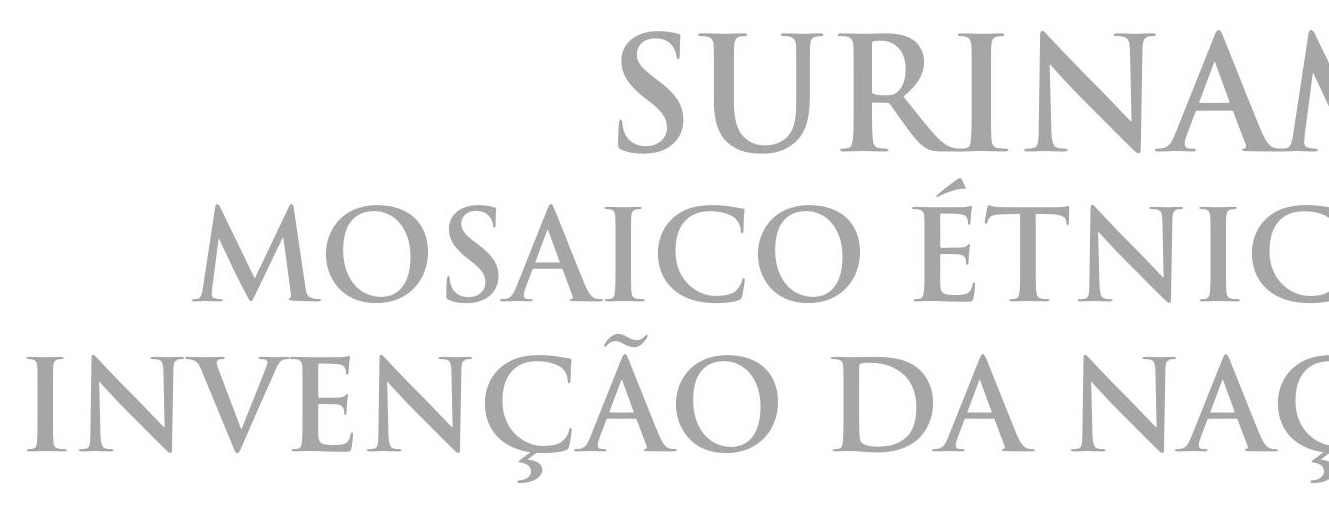




\section{SURINAME: MOSAICO ÉTNICO E INVENÇÃO DA NAÇÃO}

JOHN DA SILVA ARAUJO

UNIVERSITÉ TOULOUSE - JEAN JAURÈS 


\title{
SURINAME: MOSAICO ÉTNICO E INVENÇÃO DA NAÇÃO
}

\section{Resumo}

O presente artigo aborda a complexa sociedade surinamesa, marcada pelo histórico de imigração e pelo mito nacional da união de povos de origens diversas: Índia, China, Indonésia, África, Europa e América. Partindo do conceito de que uma nação é o conjunto de seres humanos que vive num mesmo território, constituindo uma comunidade política, com origem, história, cultura, tradições e, às vezes, língua comuns, pondero que, excetuando-se o território e a política, o Suriname não apresenta tais características. Analiso, então, as intricadas relações entre os grupos étnico-culturais, a pretensa harmonia entre eles, e o mito de constituição da nação. Palavras-chave: Suriname, grupo étnico, nação.

\section{SURINAME: ETHNIC MOSAIC AND INVENTION OF THE NA- TION}

\begin{abstract}
This article deals with the complex Surinamese society, which is marked by the history of immigration and by the national myth of unity of people with diverse backgrounds: India, China, Indonesia, Africa, Europe and America. Based on the concept that a nation is the group of human beings living in the same territory, under a political community, with common origin, history, culture, traditions and, sometimes, language; I ponder that, except for the territory and politics, Suriname does not have these characteristics. I, then, analyze the intricate relations between the ethnic-cultural groups, the alleged harmony between them, and the myth of the constitution of the nation.
\end{abstract}

Keywords: Suriname, ethnic group, nation.

\section{SURINAM: MOSAICO ÉTNICO E INVENCIÓN DE LA NACIÓN}

\section{Resumen}

El presente artículo aborda la compleja sociedad de Surinam, marcada por un histórico de inmigración y por el mito nacional de la unión de pueblos de orígenes distintos: India, China, Indonesia, 
África, Europa y América. Tomando como punto de partida el concepto de que una nación es un conjunto de seres humanos que viven en un mismo territorio, que constituyen una comunidad política con origen, historia, cultura, tradiciones y, a veces, lengua común, pondero que, exceptuando el territorio y la política, Surinam no presenta tales características. Analizo entonces las intrincadas relaciones entre los grupos étnico-culturales, la pretendida armonía entre ellos y el mito de constitución de la nación.

Palabras clave: Surinam, grupo étnico, nación.

\section{SURINAME : MOSAÏQUE ETHNIQUE ET INVENTION DE LA NATION}

\section{Résumé}

L'article que nous proposons ici met en perspective la complexe société surinamienne, marquée par l'histoire de l'immigration et par le mythe national de l'unité des peuples de différentes origines: de l'Inde, de la Chine, de l'Indonésie, de l'Afrique, de l'Europe et de l'Amérique. Basé sur le concept selon lequel une nation est l'ensemble des êtres humains vivant sur un même territoire, au sein d'une communauté politique, avec une origine, une histoire, une culture, des traditions et problablemente une langue communes, nous pensons que, à l'exception du territoire e de la politique, le Suriname n'as pas de telles caractéristiques. Sous ce rapport, nous essayerons de poser à nouveaux frais la problématique de la multiplicité des liens entre les groupes ethnoculturels, la prétendue cohésion nationale et le «mythe de la nation ».

Mots-clés : Suriname, groupe ethnique, nation.

Endereço do autor para correspondência: Av. Nazaré, 909. Edifício Belo Horizonte, Apto : 302 A. Nazaré. Belém. Pará. Cep : 66035-145.

jsaraujo@yahoo.com 


\section{INTRODUÇÃO}

A discussão sobre a invenção das tradições, trazida à tona mais precisamente por Erik Hobsbawn e Terence Ranger (1983), é uma abordagem da história dos países que causa alguns perplexos e aversões. Como tradições de nações históricas, com suas culturas e cerimoniais, como Inglaterra e França, emergidas de conhecidas epopeias milenares de reis e cavaleiros, amplamente difundidas, podem ter sido "inventadas" somente nos séculos XIX e XX?

Apesar de largamente aceito no meio dos historiadores (mesmo havendo boas críticas), o conceito da invenção das tradições pelas nações (que, apesar de surgidas mais recentemente, elaboram e se referem a tradições históricas longínquas, abalizadas em mitos fundadores) ainda se depara com situações inusitadas que continuam a causar certo desconforto a alguns Estados-nações. O livro publicado pelo historiador israelense Shlomo Sand (2008), é um exemplo. Ele elabora a desconstrução do "mito nacional", partindo do mesmo pressuposto da produção de tradições pelas nações, e das "comunidades imaginadas”, de Benedict Anderson (2002), aplicada à invenção do povo judeu. Sua obra continua a causar reações emocionadas em parte da opinião pública e acusações de antissemitismo, mas, apesar da polêmica, é um sucesso de vendas em Israel.

O campo de estudo apresentado nesse artigo, o Suriname, serve, também, como centelha para se pensar a situação complexa da invenção da tradição em países que adotam o multiculturalismo como marco constitutivo. Esse país fantástico laboratório da etnicidade mesmo possuindo pequena população, apresenta "visíveis fronteiras étnicas" - à la Fredrik Barth (1998)1, expondo a relação intricada entre o "comunitarismo" das minorias e o Estado-nação.

Abordo, ainda, o emaranhado de relações sócio-políticas nos imbróglios da diversidade cultural, mas também - a fim de apimentar mais o dissenso (papel de todo pesquisador), coloco em questão os princípios do multiculturalismo, a partir, principalmente das reflexões de Milene Doytcheva (2011).

Em países, como é o caso do Suriname, cuja égide constitutiva repousa na ideia da reunião de diversos povos, qual seria o "mito nacional"? E mais particularmente: como refletir o sistema ideológico que pauta a relação de equilíbrio entre os grupos étnicos - o apanjhat ${ }^{2}$ - no contexto da disputa política? São essas as questões que discutiremos nesse artigo.

A primeira impressão marcante do Suriname, para qualquer visitante, é de uma sociedade visivelmente dividida e consolidada em grupos étnico-culturais $^{3}$, com contornos bem definidos, que convivem num único e pequeno país: hindustanos ${ }^{4}$, javaneses, crioulos, quilombolas, chineses, indígenas etc. A partir de um olhar mais acurado e prolongado, essa primeira impressão começa a dar lugar a nuances e ambiguidades. O Suriname apresenta, ainda, disparidades em relação à maior parte do contexto latino-americano (a língua não latina, o background populacional afro-asiático, os vínculos com o Cari- 
be), o que acaba por torná-lo, apesar da proximidade, distante do Brasil.

Antes de ir além sobre as particularidades desse país, convém situá-lo geograficamente: localizado no norte da América do Sul, com área de 163.820 $\mathrm{km}^{2}$ e aproximadamente 500 mil habitantes (metade dos quais na capital), o Suriname faz fronteira, ao sul, com o Brasil, a oeste, com a República Cooperativa da Guiana, e a leste, com a Guiana Francesa; ao norte está o Oceano Atlântico. É inteiramente coberto pela floresta amazônica, exceto uma pequena faixa litorânea onde vive cerca de $90 \%$ da população e onde se encontra a capital, Paramaribo. As características ambientais são semelhantes às da Amazônia Oriental brasileira: relevo plano, clima quente e úmido, e mesmo tipo de vegetação (floresta amazônica).

Antes da chegada dos europeus, no século XVI, o seu território era habitado por indígenas aruaques e caraíbas, e durante muito tempo foi alvo de disputa entre ingleses e neerlandeses 5 . Em 1667, os Países Baixos receberam a sua posse em troca da cidade de Nova Amsterdã (Nova Iorque). Embora a presença inglesa anteceda a neerlandesa, o domínio britânico se deu, de fato, por breves períodos, e sua última ocupação ocorreu de 1804 a 1816, ano em que os Países Baixos consolidaram definitivamente o domínio sobre a região, que, na época, passou a se chamar Guiana Neerlandesa (Rosa Ribeiro 2002).

A diversidade de origem dos habitantes da colônia neerlandesa ampliou-se com a aquisição de escravos do oeste da África para o trabalho na agricultura de exportação (açúcar e cacau, principalmente), na qual estava baseada sua economia. A mão de obra escrava foi utilizada até 1863 , quando a escravidão foi abolida. Os colonizadores optaram por utilizar a, até então, bem-sucedida experiência dos britânicos na Guiana Inglesa $^{6}:$ em substituição aos escravos, contrataram trabalhadores da China, da Índia Britânica e das Índias Orientais Neerlandesas (Nederlands Oost-Indië, que, depois da independência, passaram a se chamar Indonésia), principalmente de sua ilha mais populosa, Java.

O resultado desse processo de colonização foi o que conferiu à Guiana e ao Suriname perfil diferenciado do contexto sul-americano: estão muito mais próximos do ambiente cultural caribenho. Eles integram a Comunidade do Caribe (Caricom) ${ }^{8}$, mas também a Organização da Conferência Islâmica, que congrega os países de maioria ou com significativa minoria muçulmana.

\section{- mosaico ÉtNICO-CULtURAL DO SURINAME}

A diversidade das origens étnicas dos surinameses é facilmente percebida na vida cotidiana: nos partidos políticos, nos feriados nacionais, nas línguas faladas. Ainda que existam espaços de convivência intercomunitária como a escola e os espaços públicos em geral, há, também, espaços em que a convivência intracomunitária é realçada, como os templos religiosos, onde são utilizadas as línguas específicas de cada grupo étnico-cultural (quase sempre 
ao lado do neerlandês); os cemitérios, administrados separadamente pelas instituições religiosas cristãs, muçulmanas e judias, e o crematório hindu; e os centros culturais que promovem a tradição do seu respectivo grupo. Enfim, as diferenças comunitárias se expressam em toda parte. Lá, Mahatma Gandhi e Martin Luther King não são apenas pacifistas exemplares que lutaram pela emancipação de povos oprimidos: Gandhi é, antes de tudo, um hindustano, e Luther King, um crioulo.

O Escritório Geral de Estatísticas no Suriname (Algemeen Bureau voor de Statistiek in Suriname - ABS Suriname) é o órgão oficial de pesquisas e estatísticas do país, e realiza enquetes a fim de obter dados socioeconômicos, nos quais estão incluídas informações sobre os grupos étnicos e a filiação religiosa, pois entende que "a nacionalidade e a etnicidade (aberta ou secretamente) têm sido importantes no Suriname" (ABS Suriname 2005). De acordo com dados divulgados pelo órgão em 2012, num universo de 541.638 pessoas (a população total do Suriname), havia 148.443 hindustanos, 117.567 quilombolas, 84.933 crioulos, 73.975 javaneses, 72.340 mestiços, 20.344 indígenas, 7.885 chineses e 16.151 declararam outro grupo ou desconhecido (Figura 1). Esses números nos permitem ter uma ideia geral da configuração étnica do país: os hindustanos são os mais numerosos e constituem, junto aos quilombolas, crioulos e aos javaneses, as quatro comunidades mais "importantes".

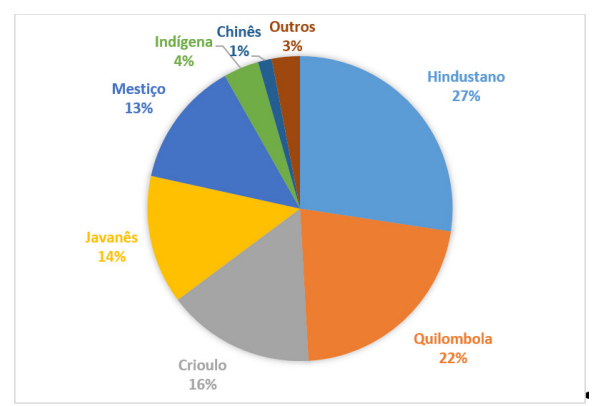

Figura 1: Composição étnica do Suriname em 2012 (gráfico elaborado a partir dos dados constantes em Algemeen Bureau Voor de Statistiek in Suriname 2012).

No Suriname, a língua oficial, o neerlandês, é amplamente empregado âmbito público formal: na imprensa, no Parlamento, nos pronunciamentos públicos, nas relações sociais formais; e o inglês assume esse papel como idioma secundário auxiliar nos contatos em que uma das partes não se expressa na língua oficial do país.

No contato informal público, predomina o Sranantongo" ou "surinamês", também conhecido como Takitaki, Nengretongo, Nengre ou Sranan. A língua foi, inicialmente, um pidgin de base inglesa, surgido da necessidade de comunicação entre os escravos africanos e os senhores coloniais (primeiramente ingleses e, depois, neerlandeses); com o fim da escravidão chegou às cidades, para onde migraram os ex-escravos. Com o decorrer dos anos, tornou-se língua franca em Paramaribo e demais cidades da área litorânea (Rosa Ribeiro 2002; Wilner 2003, 2007).

Outras línguas são usadas pelas respectivas comunidades, principalmente no âmbito doméstico e em algumas cerimônias religiosas, como o Sarnami, 
versão surinamesa do hindustani caribenho, que, por sua vez, é uma variação do hindustani falado no subcontinente indiano no final do século XIX e no início do XX, e que deu origem aos idiomas urdu e hindi modernos ${ }^{10}$; o javanês, língua oriunda da ilha de Java; o chinês, utilizado genericamente pelo ABS Suriname para designar as línguas oriundas da China; o Marrontaal, linguajar com forte influência africana falado pelos quilombolas surinameses, cujas principais variações são Saramaka, Paramaka, Aukan e Aluku; e línguas indígenas aruaque e caraíba (ABS Suriname 2004).

Em resumo, pode-se dizer que neerlandês é a língua oficial, e também, a das ciências (junto com o inglês); o javanês, o Sarnami, o chinês, etc., são as línguas tradicionais de cada grupo; o Sranantongo, a da "rua". Um surinamês de origem javanesa resumiu a situação linguística no país: "A gente aprende javanês em casa, neerlandês na escola e Sranantongo na rua".

O senso de 2012 também registrou dados relativos à filiação religiosa: naquele ano, 262.203 surinameses se declararam cristãos; 120.623, hinduístas; 75.053, muçulmanos; 9.949, religião tradicional quilombola (denominada Winti); 6.622, testemunhas de Jeová; 4.460 , religião tradicional javanesa (javanismo); 181, judeus; 4.630, outras religiões; 40.718 não tinham religião; 11.059 não responderam à questão; e 6.023 não sabiam. Em termos percentuais, os grupos religiosos no Suriname compunham o quadro mostrado na Figura 2.

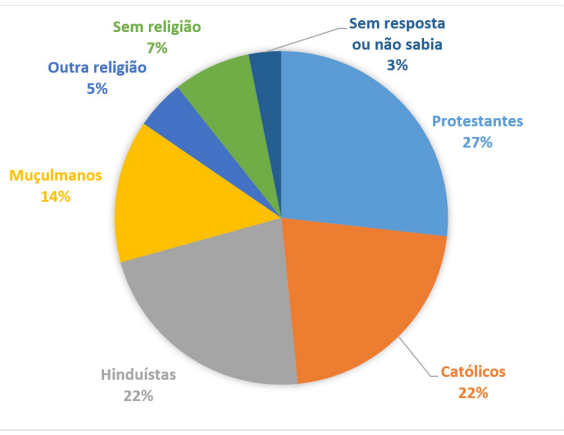

Figura 2: Composição religiosa do Suriname em 2012 (gráfico elaborado a partir dos dados constantes em Algemeen Bureau Voor de Statistiek in Suriname, 2012).

Cristianismo (catolicismo e protestantismo), hinduísmo e islamismo perfaziam, juntos, quase a totalidade da filiação religiosa da população surinamesa (85\%), dividindo a população do país praticamente em 4 blocos de confissão religiosa.

Os feriados nacionais também refletem o reconhecimento dessa heterogeneidade religiosa e étnica do Suriname. Entre os feriados comemorados em $2013^{11}$, seis referiam-se às comemorações religiosas, sendo duas celebrações hinduístas: Holi phagwah (27 de março) e Divali (3 de novembro); duas muçulmanas: fim do Ramadã (8 de agosto) e Festa do Sacrifício (15 de outubro); e duas cristãs: Páscoa (29 de março e $1^{\circ}$ de abril), e Natal (25 e 26 de dezembro). Houve, ainda 4 feriados relativos às comunidades étnicas, sendo um feriado hindustano: imigração hindustana (5 de junho); um crioulo: Abolição da escravidão $\left(1^{\circ} \text { de julho }\right)^{12}$; um indígena: Dias dos Povos Indígenas (9 de agosto); e um quilombola: Dia Nacional dos quilombolas (10 de outubro). O Ano Novo (1 ${ }^{\circ}$ de janeiro), apesar 
de não estar explicitamente vinculado a um grupo étnico ou religioso, é relacionado à comunidade cristã, já que muçulmanos, hinduístas, chineses e judeus o comemoram em outras datas, seguindo calendários próprios. Os demais três feriados nacionais comemoraram datas cívicas que abrangiam todos os grupos étnico-culturais: Dia da Revolução (25 de fevereiro), Dia do Trabalho ( $1^{\circ}$ de maio) e Dia da Independência (25 de novembro).

Vários canais de televisão aberta surinameses têm programações direcionadas especificamente para um dos grupos étnico-culturais, nas quais o idioma preponderantemente é o do grupo almejado: por exemplo, a SCTV transmite em chinês, a Trishul tem programas em hindi e a Garuda TV, em bahasa (a língua oficial na Indonésia), algumas vezes com legendas em neerlandês. Em 2012, do total, seis emissoras de televisão eram direcionadas para a comunidade hindustana, duas para a javanesa, uma para a chinesa e seis não tinham programação abertamente direcionada. Estas últimas transmitiam programação nacional, e expunham personalidades do cenário político e cultural do Suriname, sendo correntemente identificadas com a comunidade crioula, que incorpora, grosso modo, o ideal do surinamês comum, como é o caso da STVS, fundada pelo crioulo Johan Adolf Pengel. A programação das diferentes emissoras reflete a partição étnica da sociedade.

\section{MOSAICO ÉTNICO NA POLÍTICA}

O Parlamento é outro espaço oficial onde pode ser visualizada a diversidade dos grupos étnico-culturais. A partir do trabalho de campo, montei o Quadro 1, no qual listo os principais partidos políticos do Suriname em 2013 e a respectiva comunidade que representam ou, ao menos, com a qual os habitantes do país os relacionam: o Partido Nacional Democrático (Nationale Democratische Partij - NDP), do atual presidente, Desiré Delano Bouterse (mandato de 2015 a 2020), e o Partido Nacional do Suriname (Nationale Partij Suriname - NPS), do presidente anterior, Ronald Venetiaan, são apoiados sobretudo por crioulos; o Partido Reformista Progressista (Vooruitstrevende Hervormings Partij - VHP), por hindustanos; o Kerukanan Tulodo Pranatan Inggil (KTPI) ${ }^{13}$ e o Pertjajah Luhur (PL), por javaneses; e o Partido da Libertação e Desenvolvimento Geral (Algemene Bevrijdings-en Ontwikkelings Partij - ABOP), pelos quilombolas.

\begin{tabular}{|c|c|}
\hline PARTIDO & $\begin{array}{c}\text { GRUPO } \\
\text { ÉTNICO- } \\
\text { CULTURAL }\end{array}$ \\
\hline $\begin{array}{c}\text { Partido Nacional } \\
\text { Democrático (NDP) }\end{array}$ & Crioulo \\
\hline $\begin{array}{c}\text { Partido Nacional do } \\
\text { Suriname (NPS) }\end{array}$ & Crioulo \\
\hline $\begin{array}{c}\text { Partido Reformista } \\
\text { Progressista (VHP) }\end{array}$ & Hindustano \\
\hline $\begin{array}{c}\text { Kerukanan Tulodo } \\
\text { Pranatan Inggil (KTPI) }\end{array}$ & Javanês \\
\hline $\begin{array}{c}\text { Pertjajah Luhur (PL) } \\
\text { Partido da Libertação } \\
\text { e Desenvolvimento } \\
\text { Geral (ABOP) }\end{array}$ & Javanês \\
\hline
\end{tabular}

Quadro 1: Partidos políticos do Suriname em 2013. 
No Suriname atual, o ambiente engendrado por um Estado assumidamente pluriétnico e pela configuração que reifica o pertencimento comunitário foi influenciado pelo modo de colonização neerlandesa, no qual a tolerância às diferenças étnicas compunha a plataforma política desde que não interferissem nos interesses da metrópole — ou seja, não adotou o assimilacionismo como ideário, o que favoreceu a separação e a consolidação dos grupos humanos ao longo dos anos. De acordo com Fernando Rosa Ribeiro (2002), nela foram estabelecidas as fronteiras étnicas da sociedade, e assim as comunidades foram perenizadas na construção da ideia de nação, tornando-se essa uma característica não apenas desse país, mas também da África do Sul, onde as fronteiras comunitárias permaneceram após a independência e no pós-apartheid.

Assim, a identidade nacional do Suriname repousa sobre essa diversidade. Em 2011, nas ruas de Paramaribo, por exemplo, um outdoor da empresa de telecomunicações TeleSur estampava o reconhecimento da diversidade étnico-cultural surinamesa: trazia a imagem de três trabalhadores, de três diferentes comunidades étnicas, e a afirmação "This is us..." (Figura 3).

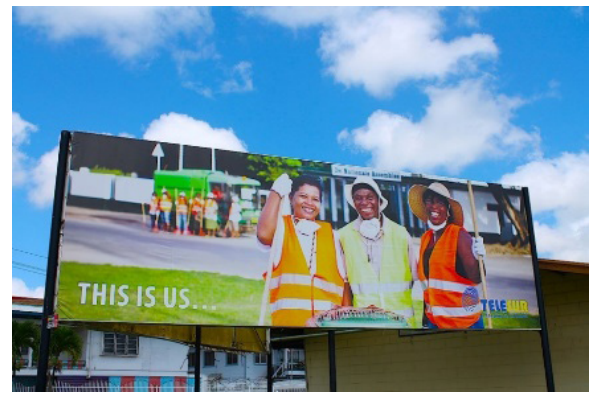

Figura 3: Outdoor da empresa de telecomunicações TeleSur, em Paramaribo, mostrando a diversidade étnica do Suriname (John Araujo 2012).

Analisando as características que nortearam a ação das metrópoles coloniais europeias, Roger Bastide enfatiza que a colonização inglesa seguiu caminhos diferentes do modelo francês, no qual os colonizadores do século XIX e XX, sob influência do Iluminismo (que forneceu as bases ideológicas para a Revolução Francesa, em 1789), agiam como soldados combatendo o obscurantismo dos povos colonizados. Os ingleses, por outro lado, adotaram o sistema de administração indireta (Indirect Rule), que legitimava o poder tradicional dos chefes nativos, e, por isso, era preciso conhecer como funcionavam esses governos, já que as mudanças necessárias para o controle político eram implantadas através deles - daí o importante papel da antropologia aplicada naquele momento, particularmente da antropologia social funcionalista criada por Malinowski (Bastide, 1998).

A administração colonial neerlandesa adotou, em certa medida, o Indirect Rule para gerir seus domínios, entre eles o Suriname, por isso a disposição em reconhecer oficialmente os hábitos dos habitantes e dar legitimidade aos ritos sociais tradicionais.

\section{O EQUILÍBRIO ENTRE GRUPOS ÉT- NICOS: O APANJHAT}

Historicamente, os grupos étnico-culturais fazem parte da gênese do Suriname, assim, eles estiveram também presentes nos símbolos do país. Em 
1954, o Suriname obteve o estatuto de país autônomo integrante do Reino dos Países Baixos (estatuto que conservou até sua independência, em 1975). Entre 1966 a 1975, adotou a bandeira que representava os seus cinco principais grupos étnico-culturais: cinco estrelas de cores diferentes ligadas por uma elipse preta que simbolizava a união harmônica desses povos no seio da nação (Oostindie \& Klinkers 2003). Embora não tenha sido oficialmente atribuída determinada estrela a determinado grupo, a relação entre as cores delas e os grupos étnicos foi feita automaticamente entre a população: a branca aos colonos europeus (Buru); a preta aos crioulos; a marrom aos hindustanos; a vermelha aos indígenas; e a amarela aos chineses (Figura 4).

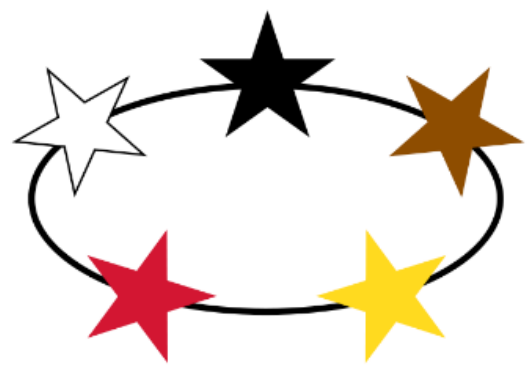

Figura 4: Bandeira do Suriname adotada entre 1966 e 1975 (quando ainda fazia parte do Reino dos Países Baixos), na qual eram evidenciados os seus cinco principais grupos étnico-culturais (Flags of the World Web Site 2013).

Várias críticas se seguiram à adoção da bandeira com cinco estrelas, e as principais colocavam em questão a representação do equilíbrio entre os grupos: as três estrelas superiores, dos Buru, crioulos e hindustanos, apontavam para fora da elipse, e as duas inferiores, dos indígenas e chineses, para dentro, e essa disposição dava a ideia de submissão destes últimos aos primeiros; a posição da estrela branca (Buru) deixava-a ao lado do mastro que hasteia a bandeira, e dessa forma ela aparecia como sustentáculo das demais, puxando-as para cima; a estrela preta (crioulos) estava na parte superior central da bandeira, em posição privilegiada, como se fosse a mais importante; e o problema principal era que javaneses e quilombolas estavam fora da representação. A fim de apaziguar essas polêmicas, a bandeira adotada após a independência contém uma estrela dourada, de cinco pontas, representando a união dos grupos étnicos do país (Campos França 2004) (Figura 5).

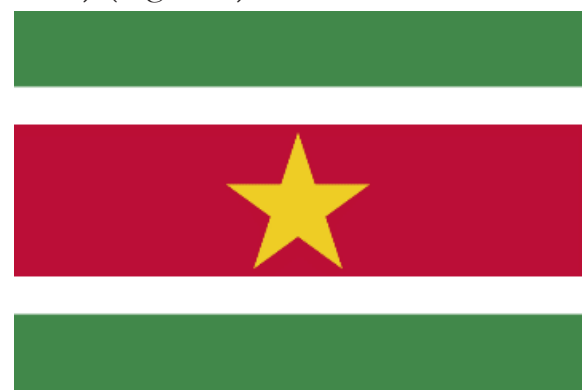

Figura 5: Bandeira do Suriname (Flags of the World 2014).

Formalmente, as instâncias administrativas se esforçam para manter o equilíbrio de forças e garantir a representação de todos os grupos. Para Edward Dew (1994, 1978), o Suriname representa um modelo na resolução dos atritos sociopolíticos que antecederam a, e se sucederam após a independência, sublinhando a política do consociativismo, na qual o poder é dirigido por uma elite multipartidária e multiétnica. A Constituição surinamesa de 
1987 manifesta essa preocupação no artigo que estabelece que as instâncias governamentais devem "respeitar a liberdade de discussão, a crítica e o reconhecimento da minoria pela maioria" (Campos França 2004:154). A fim de legitimar sua autoridade político, os grupos que chegaram ao poder com o fim do regime militar, em 1991, atribuíram novamente ênfase ao apanjhat, pelo qual reconhecem oficialmente o dever de conceder espaço representativo às comunidades étnico-culturais minoritárias.

Segundo Maria Stela de Campos França (2004), a divisão da representação da sociedade surinamesa é expressa pelo apanjhat: o estado de equilíbrio ou de balança entre as expressões públicas de todos os grupos étnico-culturais que a compõem:

“[...] o apanjabt pressupõe, por um lado, o direito e o dever de cada um dos grupos de se expressarem publicamente, e, por outro, a outorga de valor equitativo a todas as manifestações.

Ideologicamente, nenhum dos grupos étnico-culturais prevalece sobre o outro, seja na arena política, cultural, religiosa ou jurídica. A desigualdade na valorização da expressão de algum grupo provoca um desequilíbrio na balança étnico-cultural, perante o qual pode haver fortes reações por parte dos grupos que se perceberem em posição desvantajosa" (Campos França 2004:147).

O conceito de apanjhat pode ser facilmente associado ao de multiculturalismo, como podemos notar comparando-o à afirmativa de Melena Doytcheva
(2011) sobre este último: "Il est pour ses défenseurs le projet de traiter et de prendre en compte le pluralisme culturel ainsi que les rapports entre groupes majoritaires et minoritaires à l'intérieur d'une perspective d'égalité et de justice sociale » (Doytcheva 2011:5).

A aplicação do apanjhat, no Suriname, se deu no período da emergência dos direitos das minorias, do reconhecimento da diversidade cultural e do " $r e$ nouveau ethnique", nas décadas de 1960 e 1970; assim como o início da implantação de políticas com bases multiculturais no Canadá e na Austrália. Desse modo, no Suriname, o apanjhat representa o reconhecimento social e político de princípios multiculturalistas.

\section{PROBLEMAS E LIMITES DO APAN- JHAT}

Paul Tjon Sie Fat (2009) conceitua a ideologia apanjhat como a divisão equitativa de poder entre os grupos étnicos, mas mostra-se crítico a esse princípio. Diz que, na prática, a divisão se dá entre os três maiores grupos: crioulo, hindustano e javanês (mais recentemente, os quilombolas estão sendo incluídos), deixando de fora os demais grupos minoritários. Ele mostra que a aplicação desse princípio igualitário por esses três principais grupos serve, antes de tudo, para legitimar sua hegemonia política e econômica.

Como forma de etnopolítica, a ideologia apanjhat é importante geradora de identidade dos grupos étnicos, pois forja o reconhecimento oficial de uma sociedade composta por diversos seg- 
mentos étnico-"raciais", o que reifica, legitima e consolida o reconhecimento popular das diferenças comunitárias.

De acordo com Fred Constant (1994:58), apanjhat é uma palavra da língua hindi, e "votar apanjhat" significa, literalmente, "votar para os seus", ou seja, direcionar o voto para a sua própria comunidade étnico-cultural. Essa ideologia foi aplicada na política da Guiana Inglesa durante o período colonial, a partir da década de 1950, quando o Parlamento local passou a ter mais poderes e funções na administração interna. O Partido Popular Progressista (People's Progressive Party - PPP), criado em 1950 por intelectuais e trabalhadores guianeses, foi inicialmente uma organização de cunho marxista multiétnica, cujo líder, Cheddi Jagan, era um indo-guianês ${ }^{14}$. Ainda naquela década, Forbes Burnham, um afro-guianês moderado, deixou o partido e fundou o Congresso Nacional do Povo (People's National Congress $-\mathrm{PNC})$.

O desentendimento entre Jagan e Burnham deveu-se ao distanciamento ideológico: o primeiro reivindicava uma linha mais radical de aplicação dos princípios marxistas (como a expropriação da propriedade privada), enquanto o segundo defendia um socialismo mais moderado, que passaria por reformas e entendimentos com o pequeno empresariado urbano. No entanto, as divergências tiveram como pano de fundo o acirramento da tensão étnica gerada pela liderança incontestável de Jagan no partido, apoiado por indo-guianeses, principalmente os trabalhadores do setor da cana, do açúcar e da rizi- cultura - o que passava a impressão de que o PPP defendia apenas os interesses dos indo-guianeses. $\mathrm{O}$ seu desejo inicial de formação de um partido de massas que colocasse em primeiro plano demandas de classe em vez das questões étnicas foi sendo abandonado depois da cisão com Burnham e da formação do PNC, que se tornou uma força política rival. Entre 1957 e 1962 , o clamor pelo voto apanjhat virou o grito de guerra do PPP, baseado na maioria numérica dos indo-guianeses sobre os afro-guianeses, no lastro da ascensão do nacionalismo étnico indiano na Ásia (Singaravelou 1991).

A ideologia apanjhat, associando partido político e grupo étnico-cultural, passou a dar a tonalidade da disputa pelo poder da colônia e, posteriormente, da jovem nação. Dessa forma, a associação entre comunidade étnica e apoio ao partido que a representava constituiu-se a nova "arma de campanha" do PNC e do PPP, contribuindo para o sucesso eleitoral das duas agremiações junto ao seu respectivo eleitorado. Por isso, o voto apanjhat, apesar de não ser o lema oficial do PPP (pois este pregava oficialmente a melhoria de vida para todos os guianeses), tornou-se o seu slogan popular para angariar votos nas eleições de 1961. O PNC, igualmente, voltou-se principalmente para sua base afro-guianesa, polarizando a disputa política em torno da questão étnico-racial.

$\mathrm{O}$ argumento do apanjhat na Guiana evocava a promessa de melhoria de vida dos indo-guianeses: os empresários teriam garantido o mercado para seus produtos, os professores teriam 
emprego, os mais bem instruídos teriam acesso às funções públicas, os camponeses teriam acesso à terra e os trabalhadores da indústria de açúcar teriam melhoria financeira. Em síntese, votar na representação política do grupo comunitário garantiria a prosperidade para todos os indo-guianeses; o voto apanjhat ajudaria os indianos a ajudar os indianos: "Apanjaht would help the Indians to help the Indians" (Gerrit de Kruijf 2006:81).

Anteriormente às tensões raciais envolvendo indo e afro-guianeses (logo antes e depois da independência da Guiana), a "racialização" das relações sociais já era evocada na legitimação da dominação colonial. Na Guiana pós-escravidão, o monopólio do poder político pela minoria branca permitiu utilizar o aparelho do Estado para institucionalizar as desigualdades sociais e políticas, e, assim, para subjugar a maioria da população, lembrando que a questão racial serviu de fundamentação lógica para justificar a supremacia (Moore 1987).

\section{MULTIETNICIDADE E O SURGIMEN- TO DA NAÇÃO}

A emergência da Guiana como unidade com autonomia interna trouxe a possibilidade de ascensão política e social a uma classe até então posta à margem das decisões. A transformação de súditos da coroa inglesa em neófitos cidadãos colocou em pauta questões já vivenciadas desde o século XVIII na Europa, por ocasião do arrefecimento do pensamento religioso, da emergência do nacionalismo, e do surgimento da pátria como o novo elemento identitário (Geary, 2008).

De acordo com Hobsbawn (1983, 1962), a legitimidade dos reis repousava em resoluções divinas, restando aos habitantes dos reinados, obediência ao soberano. Com a formação dos Estados nacionais, os governantes e grupos dominantes se viram confrontados com a necessidade de estabelecer e preservar a obediência, a lealdade e a cooperação dos cidadãos, precisando, assim, buscar de legitimidade aos olhos deles. Era, então, necessário - como foi o caso, bem mais recentemente na Guiana - criar condições para a difusão da ideia de "nação": uma comunidade política imaginada, ao mesmo tempo limitada e soberana; e, consecutivamente, dos Estados nacionais (Anderson 2002).

Eric Hobsbawn e Ranger (1983) utilizam precisamente esse contexto europeu na análise da invenção das tradições, direta ou indiretamente operada por agentes sociais e grupos políticos em busca de dar legitimidade às novas estruturas de poder. Ao evocar as rápidas transformações que as sociedades europeias viveram no final do século XIX, assim como a invenção das tradições produzida a fim de garantir legitimidade ao poder constituído, Hobsbawn (1983) precisa que os novos contextos sociais exigiam a invenção de novos instrumentos políticos que assegurassem a identidade, a coesão e estruturação das relações sociais.

O desenvolvimento de alianças com as demais forças políticas — e os demais grupos étnico-culturais, ainda que 
minoritários - fez parte dos mecanismos de reconhecimento e legitimação do poder. No caso guianês, a invenção de uma tradição ligada à origem comum e à memória coletiva milenar do subcontinente indiano foi uma estratégia essencial para o grupo indo-guianês na sua busca pela hegemonia política. Assim, a análise crítica dos conflitos de interesses presentes na sociedade guianesa atual, deve indispensavelmente levar em conta a disputa política na qual o apanjhat esteve implicado.

Esse passeio pela história da implementação da ideologia apanjhat no contexto guianês nos permitirá melhor discutir a maneira da sua utilização no Suriname, porque o processo de independência, assim como o recurso a essa ideologia com fins políticos ocorreram anteriormente na Guiana. Podemos começar mencionando que no Suriname, em 1949, foi formado um partido político ligado à comunidade hindustana, o Partido Hindustano Unido (Verenigde Hindostaanse Partij — VHP), pela fusão de três partidos que, separadamente, a representavam: o Partido Muçulmano (Moeslim Partij), fundado em 1946; o Partido Político Hindustano-Javanês (Hindostaans-Javaanse Politieke Partij - HJPP), fundado em 1947; e o Partido Hindu (Hindoe Partij), fundado em 1947 (VHP 2013). Em 1973, o VHP passou a se chamar Partido Reformista Progressista (Vooruitstrevende Hervormings Partij), mantendo a mesma sigla, cujo slogan manifestava claramente a ambição reunir os hindustanos dos diversos grupos religiosos:
"Hindu, muçulmano, sique, cristão. Eles são todos irmãos.

A Índia é a mãe de todos eles" (Chickrie 2008:12) $^{15}$.

Como já mencionei, entre 1954 e 1975 , o Suriname foi elevado ao status de país integrante do Reino dos Países baixos, com plena autonomia interna, à exceção das áreas da defesa e política externa, em bases iguais às das Antilhas Neerlandesas e às dos Países Baixos (a unidade europeia do Reino) Assim foi formado um Parlamento com poderes sobre os assuntos internos, e o VHP, além de pleitear o apoio popular do seu próprio grupo (os hindustanos), buscou se aliar às organizações políticas que representavam as demais comunidades étnico-culturais, mesmo as minoritárias, pois eram importantes para o reconhecimento e a estabilidade do governo do novo Estado - portanto, a ideologia apanjhat foi evocada, pois respondia exatamente a essa conjuntura - , e acabou se coligando com o NPS, o que significou, na prática, a aliança entre os dois principais partidos e também entre os dois principais grupos étnicos do Suriname: hindustano e crioulo. Ou seja, não se tratou de uma livre e simples escolha de harmonia multicultural: a conjuntura política anterior à independência forjou as condições que conduziram a jovem nação ao apanjhat.

O recurso ao apanjhat mostra bem que nesse contexto, o grupo político precisa inicialmente ser reconhecido como representante legítimo da comunidade étnico-cultural; mas também, num segundo momento, buscar congregar o conjunto da sociedade que ele governa, 
a fim de ter legitimidade como dirigente do Estado e da nação.

\section{NACIONALISMO VERSUS O APAN- JHAT E AS COMUNIDADES ÉTNICAS}

A chancela do Estado surinamês ao reconhecimento dos grupos étnico-culturais, os reifica e consolida na estrutura sócio-política, moldando, inclusive, as acepções comportamentais dos grupos étnico-culturais. A atribuição de características morais e psicológicas é perceptível nas relações sociais surinamesas: na acepção popular, os indígenas, por exemplo, seriam dados ao alcoolismo, os chineses, à avareza, e os quilombolas, à brutalidade. Essa tendência a atribuir valores diferenciados para cada grupo, como se fizessem parte da essência de cada cultura, não é exclusividade do Suriname, já que está presente na própria ideia do multiculturalismo. Milene Doytcheva corrobora essa afirmativa ao detectar exatamente essas características no conjunto de ideias a ele associada:

«Le culturalisme est enfin un essentialisme. Il véhicule l'idée selon laquelle les cultures possèdent une essence, un caractère, voire une âme, à l'image des êtres vivants. Cette personnification de la culture est à la base de certaines versions de l'argument multiculturel d'après lesquelles, comme les plantes et les valeurs propre en raison de laquelle elles sont dignes de protection. Cette métaphore organique montre pourtant vite ses limites. Ne formant pas des ensembles cohérents et homogènes, la culture n'a pas non plus d'existence propre et, par conséquent, ne peut être appréhendée en dehors des individus et des cadres sociaux qui l'incarnent" (Doytcheva 2011:103).

De forma semelhante aos dilemas enfrentados em outros países onde são aplicadas políticas multiculturais (Robin Azevedo 2006), a configuração da sociedade surinamesa sob o modelo apanjhat a coloca em face de duas situações preocupantes:

A primeira é que o reconhecimento oficial das comunidades pelo Estado pressupõe a formação de partidos políticos corporativos, que buscam, em primeiro plano, atender os interesses do grupo étnico-cultural que eles representam. Esse é o caso, grosso modo, da estrutura partidária no Suriname. Se, por um lado, esse tipo de estrutura partidária permite às menores comunidades ter representantes que lutam por seus interesses no Parlamento (como é o caso dos chineses), por outro, ele permite igualmente que os grupos numericamente maiores mantenham sua dominação sobre o cenário político. Ora, essa lógica, na qual prepondera a questão do pertencimento "racial", permite a legitimidade da ação corporativa (que busca beneficiar a própria comunidade), e mascara as diferenças socioeconômicas dentro do mesmo grupo étnico-cultural - a elite econômica hindustana, por exemplo, alardeia que defende interesses comuns a todos os hindustanos, camuflando as diferenças sociais, econômicas e de classe ${ }^{16}$.

O discurso oficial que apresenta a ideologia apanjhat como um princípio que defende o equilíbrio, não se coaduna com a realidade política, pautada pela 
disputa, camuflando, também, interesses políticos e de poder. Georg Simmel (1992), ao relatar a necessidade do conflito, por ser um componente das relações sociais, traz à tona a incongruência do discurso sobre a harmonia social (como é o caso do apanjhat), já que o conflito é um componente necessário nas relações sociais à medida que permite que as diferenças sejam resolvidas, pois a partir dele são engendrados novos arranjos nas disposições das relações.

A segunda, como já mencionei acima, a luta por interesses corporativos, legitimada pela ideologia apanjhat, deixa em aberto a possibilidade de um partido que represente um grupo numérica e economicamente majoritário instalar uma hegemonia de poder, validando, na prática, a supremacia de um grupo étnico-cultural sobre os demais, evocando conotações raciais e racistas. Validado pelo apanjhat, a denúncia de prática de racismo perde o significado, já que tradicionalmente cada grupo étnico ("raça", na linguagem coloquial) defende justamente os seus próprios interesses frente aos interesses dos outros.

Para Campos França (2004), a sociedade plural surinamesa, fundamentada em comunidades étnico-culturais, teria surgido em virtude da ausência da construção de uma sociedade imaginada, nos termos de invenção das tradições, de Eric Hobsbawn. $\mathrm{Na}$ concepção da autora, os países jovens passariam por estágios sucessivos de invenção das tradições, para então se constituírem verdadeiramente em nações. Ora, o Suriname, cuja indepen- dência ocorreu tardiamente (em 1975), estaria iniciando o caminho rumo à superação das fases lineares, subsequentes e necessárias para a construção de um nacionalismo que desemboque no estabelecimento da nação propriamente dita.

Por seu lado, Eric Hobsbawn (1983, 1990) enfatiza que as nações foram criadas a partir da invenção da tradição da nação, da invenção da tradição de um povo e da invenção do próprio povo; Roy Wagner vai além dessa ideia ao afirmar que não somos responsáveis apenas pela invenção das tradições das nações: num âmbito mais amplo, inventamos os produtores da cultura e a própria cultura (Wagner 2010). Ao tomar esses autores, parece-nos que as nações não marcham rumo a um modelo idealizado de homogeneização. Assim, no Suriname, a tradição nacional inventada baseia-se, não sobre a ideia de uma nação com população uniforme, mas justamente nos grupos étnico-culturais imaginados (idealizados como homogêneos). A invenção de comunidades com origem comum, uniformes e homogêneas (pelo menos no imaginário), vem, portanto, opor-se ao modelo do nacionalismo uniformizante anticomunitarista e, por isso, "anti-apanjhat". Assim, no Suriname, não se trata da ausência de construção de sociedade imaginada ou de carência de invenção de tradição, mas de ausência de uma só e única comunidade hegemônica que represente o típico surinamês e que encarne a nação homogênea imaginada. Contrariamente a esse arquétipo, a construção da nação surinamesa se fundamenta sobre 
a invenção de diferentes tradições baseadas em cada um dos seus grupos étnico-culturais. Podemos, então, nos interrogar sobre as razões pelas quais a construção da nação surinamesa seguiu esse modelo e não outro.

Diferentemente dos países da América Latina, onde, após a independência, descendentes de colonos europeus, nascidos nas colônias, constituíram certa elite econômica e conduziram o processo de emancipação política, a imensa maioria da elite colonial do Suriname - os neerlandeses e seus descendentes - partiu do país no ano da independência e logo depois dela, de tal modo que o Suriname se encontrou dividido nas mãos dos demais grupos. Ora, como já precisei anteriormente, não há um grupo étnico-cultural que constitua uma maioria (que perfaça mais de $50 \%$ da população), assim não há o "típico surinamês" que poderia encarnar o "modelo" ou a identidade nacional.

De certa forma, no entanto, o discurso de alguns crioulos procura encarnar o surinamês ordinário em sua comunidade, quando se referem a hindustanos, javaneses e chineses como "asiáticos", atribuindo-lhes conotação de forasteiro. Deste modo, os crioulos representariam um nível diferenciado de pertencimento e de enraizamento à essencialidade surinamesa enquanto que os outros, devido suas origens asiáticas, teriam um menor nível de pertencimento ao país. Seguindo essa lógica, iniciativas do governo atual, liderado pelo NDP, partido sustentado principalmente por crioulos, procura promover valores que seriam genuina- mente surinameses - o exemplo alto dessas iniciativas é o fato de o Sranantongo (língua originalmente crioula) ter sido elevado a símbolo nacional ${ }^{17}$.

O campo ideológico do NDP situa-se entre o socialismo e o nacionalismo de esquerda. O grupo político que fundou o partido em 1987 já esteve no poder anteriormente através de golpe de estado perpetrado em 25 de fevereiro de 1980. Naquela ocasião o grupo havia polarizado o nacionalismo (e o princípio da luta de classes) ao apanjhat. A política nacionalista buscava a superação do apoio automático do cidadão ao grupo político que representava a sua comunidade étnico-cultural, pois significava um empecilho para a expansão da base de sustentação do partido governista, ou seja, essa ideologia é um campo político-ideológico oponente ao grupo que hoje dirigia o país. Nesse sentido, o modelo de voto ideológico nacionalista choca-se com o padrão de voto étnico-comunitário.

O modelo de sociedade uniforme e homogênea ("anti-apanjhat") também já foi usado para outros fins. Foi, por exemplo, o caso da declaração oficial de paz de 1992, que se seguiu aos acordos entre as forças governamentais, os grupos que elas apoiavam e o grupo guerrilheiro quilombola, o Jungle Commando (Comando da Selva), e que oficialmente pôs fim à guerra civil. Ao mesmo tempo essa declaração suprimiu o reconhecimento do direito dos grupos quilombolas sobre as terras que historicamente dominavam (e que, na prática continuam a dominar) desde os acordos que reconheciam sua autonomia, assinados entre eles e os 
colonizadores neerlandeses, no século XVIII. A justificativa principal para essa supressão do direito dos quilombolas sobre as suas terras era de que a lei republicana tem por princípio o tratamento igualitário a todos os cidadãos e a supremacia dos interesses nacionais e do desenvolvimento do país na sua totalidade, não reconhecendo direitos (ou privilégios) específicos de cada grupo étnico-cultural (Price 2013).

\section{CONSIDERAÇÕES FINAIS}

No Suriname, o reconhecimento dos grupos étnico-culturais e a aplicação do apanjhat mostram-se limitadas na efetivação da pretensa harmonia e equilíbrio. $\mathrm{O}$ modelo parece, além da fonte constitutiva do mito nacional surinamês, fazer parte do cenário de disputa política, no qual grupos expressam suas diferenças ideológicas a fim de cativar sua base de apoio.

Buscando traçar tipologias para melhor compreender os campos político-ideológicos contendedores, e seguindo o instrumento heurístico weberiano de criação de tipos ideais para interpretar o campo de pesquisa, proponho o seguinte modelo: um primeiro campo representado na política pela orientação (ou discurso) que enfatiza o nacionalismo de esquerda, a integração com a América Latina e o Caribe, e a universalização do tratamento dispensado aos surinameses, confronta outro campo cuja orientação (ou discurso) enfatiza o desenvolvimento econômico, os laços com os Países Baixos e o equilíbrio, assentado no apanjhat, entre as diversas comunidades étnico-cultu- rais que constituem o Suriname. Eles representam, entretanto, apenas tipos ideais, assim essas categorias constituídas mostram permanente construção, desconstrução e reconstrução social, e, desse modo, nesse país as relações (algumas vezes contraditórias) entre os dois modelos com princípios antagônicos contendedores se reelaboram permanentemente, dando lugar a situações ambíguas e mais complexas do que aparentam. O KTPI, por exemplo, abertamente sustentado pela comunidade javanesa (Allen 2013) e antigo parceiro do VHP (apoiado pelos hindustanos) e do NPS (apoiado pelos crioulos) no apanjhat, está atualmente na base de apoio do atual governo dirigido pelo NDP, que, como vimos, se diz "anti voto apanjhat". Podemos, assim, perceber por esse exemplo, que as duas ideologias constantemente servem também de estratégias políticas e que os partidos podem adotar uma ou outra postura de acordo com o contexto político e a conjuntura que se apresenta.

\section{NOTAS}

${ }^{1}$ Cuja abordagem expõe as ambiguidades da fabricação da fronteira entre "nós" e os "outros, mostrando que os grupos étnicos só têm significado em contexto específico.

2 Também escrito apanjaht.

${ }^{3}$ Utilizo preferencialmente o termo "étnico-cultural" para designar as comunidades étnicas que compõem o Suriname por ser o nome utilizado universalmente pelos surinameses (sobretudo nos documentos formais). Eles utilizam também outros termos, tais como "raça" e grupo. 
${ }^{4}$ Hindustani, em Sranantongo, termo que designa os surinameses de ascendência indiana.

${ }^{5}$ Utilizo os vocábulos neerlandês, neerlandesa e Países Baixos para me referir ao gentílico, à língua e ao Reino dos Países Baixos, respectivamente, e não as variantes imprecisas holandês, holandesa e Holanda, já que Holanda refere-se apenas a duas das doze províncias que constituem o país (Holanda do Norte e Holanda do Sul), apesar de ser a forma correntemente utilizada em algumas línguas, caso do português e do francês, para designar todo o país.

${ }^{6}$ Portugueses das Ilhas Madeira foram contratados para assumir os trabalhos nas lavouras na Guiana Inglesa, mas a experiência foi suplantada pela contratação de trabalhadores asiáticos (Menezes 1995; Daly 1974).

${ }^{7}$ Índia Britânica foi a denominação genérica das colônias do Império Britânico no subcontinente indiano entre os anos de 1858 e 1947, que incluía os territórios atuais do Paquistão, da Índia, de Bangladesh e de Mianmar.

${ }^{8}$ Bloco de cooperação econômica e política dos países da região caribenha, anteriormente chamado "Comunidade e Mercado Comum do Caribe".

${ }^{9}$ Sranan = Suriname; tongo = língua, ou seja, literalmente o termo significa "língua do Suriname".

${ }^{10}$ Urdu é o idioma nacional da República Islâmica do Paquistão. É considerado, por alguns linguistas, dialeto do híndi (língua oficial na Índia), do qual difere especialmente na forma escrita e literária, pois o urdu escrito possui influência do persa, enquanto o modelo literário do híndi é o sânscrito. O urdu é escrito com caracteres árabes e persas; o híndi, com o alfabeto devanágari. Desde a criação da fronteira entre a Índia e o Paquistão (1947), motivos políticos e religiosos vêm sendo usados para o aprofundamento das diferenças entre os dois idiomas, o que já afetou a escrita: da esquerda para a direita em híndi e na direção inversa em urdu.

${ }^{11}$ Os dias dos feriados surinameses de 2013 foram referidos segundo: $\mathrm{Q}++$ Studio the Professional Source Of World Public Holidays, 2013.

${ }^{12} \mathrm{O}$ Keti Koti celebra o fim da escravidão, é comemorado pelos crioulos. Os quilombolas não se consideram atingidos por esse fato já que seus ancestrais não foram submetidos à escravidão.

${ }^{13}$ Partido fundado em 1949 pelo javanês Iding Soemita, com o nome de Kaum Tani Persatuan Indonesia. Posteriormente mudou de nome, mas manteve a mesma sigla (Nederlandse Publieke Omroep 2013).

${ }^{14}$ Diferente do Suriname, onde os de origem indiana são denominados hindustanos (Hindustanis), os guianeses de ascendência indiana são denominados localmente de indo-guianeses (Indo-Guyanese), "índios orientais" (East Indians) ou simplesmente indianos (Indians).

${ }^{15}$ "Hindu, Muslim, Sikh, Isai. Sab bai bhai bhai. Bharrat mata sab ke mai. Hindu, Muslim, Sikh and Christians. They are all brothers. India is the mother of them all".

${ }^{16}$ Uma excelente discussão sobre os desafios da questão étnica e identitária pode ser encontrada na obra Michel Agier (2013).

${ }^{17}$ Esta é a segunda gestão do presidente Desiré Delano Bouterse. Entre 1980 e 1987, ele foi o presidente de fato do Suriname, quando o país esteve sob regime militar. Naquele período, ele também lançou mão de tais iniciativas, como a criação do Ministério da Cultura, com o objetivo de promover a cultura surinamesa (com o provável intuito de defini-la); a obrigatoriedade de cantar o hino nacional diariamente nas escolas (Campos França 2004); e a cria- 
ção da versão oficial do hino nacional em crioulo surinamês, o Sranantongo.

\section{REFERÊNCIAS}

Agier, M. 2013. La condition cosmopolite: l'anthropologie à l'épreuve du piège identitaire. Paris: La Découverte.

Algemeen Bureau Voor De Statistiek in Suriname. 2012. ABS Census Uitslag. Disponível em: <http://www.statistics-suriname.org/index.php/censuskantoor/ abs-census-uitslag-2012>. Acesso em: 6 jan. 2016.

2004. Census profile at district level. Disponível em: <http://www.statistics-suriname.org/index.php/statistieken/ downloads/category/28-censusstatistieken-2004>. Acesso em: 22 ago. 2012.

Algemeen Bureau Voor De Statistiek in Suriname/Censuskantoor. 2005. Landelijke Resultaten. Volume I: Demografische en Sociale karakteristieken. Suriname in Cijfers. 213. Paramaribo: ABS/Censuskantoor.

Allen, P. 2013. Mulihn Mulih nDjowo: Repatriation and Nostalgia for Home Among the Javanese of Suriname. Indonesian Studies Working Papers 16:1-17. Sidney.

Anderson, B. 2002. L'imaginaire national: réflexions sur l'origine et l'essor du nationalisme. Paris: La Découverte,

Barth, F. (1969) 1998. Introduction, in Ethnic groups and boundaries: the social organization of culture difference. Long Grove: Waveland.

Bastide, R. 1998. Anthropologie appliquée. Paris: Stock.

Campos França, M. S. de. 2004. Apanjaht: a expressão da sociedade plural no Suriname. Tese de doutorado, Departamento de Antropologia, Universidade de Brasília, Brasília.

Chickrie, R. S. Surinamese Muslims in a plural society. Disponível em: <http://www.cari-
bbeanmuslims.com/articles/981/1/Suriname-Muslims-in-a-plural-society-/page1. html>. p. 12. Acesso em: 22 dez. 2008.

Constant, F. 1994. Religion, ethnicité et politique en Caraibe. Revue Française de Science Politique 44(1):49-74.

Daly, V. T. 1974. The making of Guyana. Oxford: Macmillan Caribbean.

Dew, E. 1978. The difficult flowering of Surinam: ethnicity and politics in a plural society. The Hague: Springer Science+Business Media B.V.

Dew, E. 1994. The trouble in Suriname, 1975 1993. Westport: Praeger.

Doytcheva, M. 2011. Le multiculturalisme. Paris: La Découverte.

Flags of the World. Suriname - Colonial Flags. Dutch Overseas Territory Flag (19661975). Imagem: Mark Sensen, 25 mar. 2006. Disponível em: <https://flagspot.net/flags/sr-nl.html>. Acesso em: 3 dez. 2013.

Flags of the World. Suriname. Republiek Suriname, Republic of Suriname. Imagem: Željko Heimer, 30 jan. 2003. Disponível em: <https://flagspot.net/flags/sr.html>. Acesso em: 3 jan. 2014.

Fry, P. 2005. A persistência da raça: ensaios antropológicos sobre o Brasil e a Africa austral. Rio de Janeiro: Civilização Brasileira.

Geary, P. J. 2008. O mito das nações. A invenção do nacionalismo. Lisboa: Gradiva.

Gerrit de Kruijf, J. 2006. Guyana junction: globalisation, localisation, and the production of East Indianness. Amsterdam: Dutch university press.

Hobsbawm, E. 1962. The Age of Revolution, 1789-1898. Londres: Weidenfeld \& Nicolson.

Hobsbawm, E. 1983. Mass-producing traditions: Europe, 1870-1914, in The invention of tradition. Organizado por E. Hobsbawn 
\& T. Ranger, pp.263-308. Cambridge: Cambridge University Press.

Hobsbawm, E. 1990. Nações e nacionalismo desde 1780: programa, mito e realidade. Rio de Janeiro: Paz e Terra.

Hobsbawm, E., e T. Ranger. 1983. The invention of tradition. Cambridge: Cambridge University Press. Larousse Dictionnaire de Français. Disponível em: <http://www.larousse.fr/dictionnaires/francais $>$. Acesso em: 15 jan. 2016.

Macagno, L. 2005. Outros muculmanos: islão e narrativas coloniais. Lisboa: Imprensa de Ciências Sociais.

Menezes, M. N. 1995. The Portuguese of Guyana: a study in culture and conflict. Gamdi-Ananda: Ananda Press.

Moore, B. L. 1987. Race, power, and social segmentation in colonial society. Guyana after Slavery 1838-1891. Caribbean Studies 4. Philadelphia: Gordon and Breach.

Nederlandse Publieke Omroep. KTPI Kerukanan Tulodo Pranatan Inggil. Disponível em: <http://nos.nl/artikel/146488-ktpi-kerukanan-tulodo-pranatan-inggil.html>. Acesso em: 21 dez. 2013.

Oostindie, G., e I. Klinkers. 2003. Decolonising the Caribbean: dutch policies in a comparative perspective. Amsterdam: Amsterdam University Press.

Poutignat, P., e J. Streiff-Fenart. 1995. Théories de l'éthnicité. Paris: PUF.

Price, R. 2013. Les premiers temps: la conception de l'histoire des Marrons saamaka. La Roque d'Anthéron: Vents d'ailleurs/Ici \& Ailleurs.

Robin Azevedo, V. 2006. (Des)illusions des politiques multiculturelles. L'Ordinaire latino-américain. 204. Toulouse.

Rosa Ribeiro, F. 2002. A construção da nação (pós-)colonial: África do Sul e Su- riname, 1933-1948. Estudos Afro-Asiáticos 24(3):483-512. Rio de Janeiro.

Sand, S. 2008. Comment le peuple juif fut inventé. Paris: Fayard.

Simmel, G. 1992. Le conflit. Paris: Circé.

Singaravelou, P. 1991. Les Indiens de la Caraibe. Tome 3. Paris: L'Harmattan.

Tjon Sie Fat, P. B. 2009. Chinese new migrants in Suriname: the inevitability of ethnic performing. Amsterdam: Amsterdam University Press.

Vooruitstrevende Hervormings Partij — VHP. [sans titre] Disponível em: <http:// www.vhp.sr>. Acesso em: 21 dez. 2013.

Wagner, R. 2010. A invenção da cultura. São Paulo: Cosac Naify.

Wilner, J. 2003. Wortubuku Ini Sranan Tongo: Sranan Tongo - English Dictionary. $4^{\mathrm{a}}$ ed. $\mathrm{Pa}-$ ramaribo: Summer Institute of Linguistics, Disponível em: <http//:www.sil.org/américas/suriname/Index.html $>$. Acesso em: 18 nov. 2007.

Wilner, J. 2007. Wortubuku Ini Sranan Tongo: Sranan Tongo - English Dictionary. $5^{\mathrm{a}}$ ed. Paramaribo: Summer Institute of Linguistics, Disponível em: <http://www-01.sil.org/ americas/suriname/Sranan/STEng.pdf $>$ Acesso em: 20 dez. 2013.

Recebido em 02/01/2017

Aprovado em 29/02/2017 